Portland State University

PDXScholar

\title{
Music Education as a Potential Mediator for Social Decline
}

Gabriel V. Trees

Portland State University

Follow this and additional works at: https://pdxscholar.library.pdx.edu/honorstheses

Part of the Child Psychology Commons, Music Education Commons, and the Social Psychology Commons

Let us know how access to this document benefits you.

\section{Recommended Citation}

Trees, Gabriel V., "Music Education as a Potential Mediator for Social Decline" (2020). University Honors Theses. Paper 873.

https://doi.org/10.15760/honors.894

This Thesis is brought to you for free and open access. It has been accepted for inclusion in University Honors Theses by an authorized administrator of PDXScholar. Please contact us if we can make this document more accessible: pdxscholar@pdx.edu. 
Music Education as a Potential Mediator for Social Decline

by

Gabriel Trees

An undergraduate honors thesis submitted in partial fulfillment of the requirements for the degree of

Bachelor of Science

In

University Honors

And

Psychology

Thesis Advisor

Dr. Fred Sly

Portland State University

2020 
"Someone asked me why people sing

I answered that they sang for many of the same reasons birds sing

$$
\begin{aligned}
& \text { they sing for a mate } \\
& \text { to claim their territory }
\end{aligned}
$$

or simply to give voice to the delight of being alive

in the midst of a beautiful day"

--Linda Rondstat 


\begin{abstract}
Many cultures around the world are experiencing a decline in social wellness (Welch et al, 2014). This may be attributed to the decrease in quality and quantity of social connections people have been experiencing in recent times (Bruce et al., 2019; Konrath et al, 2011). Among the activities that seem to help humans feel connected and accountable to each other are the community singing, dancing, and drumming that has been part of our human heritage since before the beginning of written history (Buren et al., 2019; Harvey, 2018; Kirschner \& Tomasello, 2010; Loersch \& Arbuckle, 2013; Maury \& Rickard, 2016; Schellenberg et al., 2015). Active participation in group music making has been shown to promote prosocial attitudes and behaviors (Good \& Russo, 2016; Ilari, Helfter, \& Huynh, 2020; Maury \& Rickard, 2016; Williams et al., 2015). Music education for preschoolers and primary school students may be an effective method of providing opportunities for our youth to cultivate social skills, and could be an important step towards reversing our apparent current social decline.
\end{abstract}

\title{
Research Question
}

Can the apparent decline in social wellness be explained by a decrease in social bonding opportunities imposed by our modern lifestyles? If so, could implementing music education in pre-schools and primary schools promote higher levels of prosocial attitudes and behaviors for our youth, and result in greater social wellness?

\section{Introduction}

Our culture seems to be experiencing a decline in social wellness (Murthy, 2017; Weinberger et al., 2018; Welch et al, 2014). There has been a decrease of citizens' 
engagement in efforts to improve their communities, how favorable they regard their leaders, and their level of trust in each other (Welch et al, 2014). Mental health in the United States is deteriorating (Jain \& Jain, 2020; Weinberger et al., 2018), with depression and suicide rates rising consistantly for many years (Weir, 2019), and people having less and less social connections (Bruce et al., 2019; Konrath et al., 2011). Although it seems highly unlikely that a single explanation for such a complex and widespread phenomenon exists, there are many possible contributors. One is the disparity between the wealthy and the poor, which is at an all time high, especially in the United States (Shaer, 2018). The presence of this kind of extreme economic inequality has historically led societies to having higher rates of violence and less solidarity among their people (Tayag, 2017). Another possible explanation is the increasing use of mobile technology and social media, which have been found to have strong correlations with anxiety and depression (Bettmann et al., 2020). Less obvious, but perhaps even more important, is the shift in our cultural relationship to music over the last 1600 years from interactive group behavior to passive solitary listening (Attali, 1985.) Whatever is to blame, humankind seems to be on a dangerous course towards more isolation and less cooperation as a result.

\section{Personal Relationship to the Question}

I am intimately familiar with the power that music has for bringing people together. Over the last twenty-plus years as a performing musician, the deep and unique bonds I have developed through playing music are precious to me. Many of the times I have felt the most complete have been when I was in the flow with a musical 
ensemble, in front of a crowd of engaged people. Nothing compares to the way that feels for me.

Growing up in the solitude of being the only child of absent parents, music was my connection to the world. Records and radio were my best friends, and I loved them dearly. Although there were no music classes or band opportunities offered at any of the schools I attended, I was lucky enough to have had the initiative to develop musical skills independently. Playing music provided me with a way to spend my time productively, and helped me stay out of the trouble many of my friends were getting themselves into. After graduating from high school, I chose to forgo a formal education to pursue a career as a professional musician.

Music has been my guiding light; I've learned most of what I know about myself and the world I live in from studying and performing music. As someone who had very little socialization, music has been crucial to my learning how to work and play well with others. Regardless of one's talent or ability, if you can't get along with the other musicians you work with, especially in cramped quarters when away from home for long stretches of time, you will not be invited to the next gig. Also, being part of a team that is writing or recording music has shown me how to focus on the way my contributions improve a project as a whole, rather than what serves my individual needs. Most of all, music has taught me how to be patient and listen carefully. These are just a few of many lessons I learned through making music that I also apply to all my relationships. Having these skills has helped me to be a much better friend, family member, and citizen than I ever could have been without them. 
Over the last several years, I have observed people appearing to become more and more isolated and estranged from each other while, paradoxically, appearing to be increasingly connected at the same time. As a result, I have wondered if the quality of connections I experience as a working musician promote a sense of peace and harmony that seems to be increasingly missing in our culture today. I decided to use this project as an opportunity to synthesize my background as a musician with my current passion and academic pursuit of psychology to explore the relationship between music and social wellness.

\section{Research Method}

For this project, I performed an extensive literature review and synthesis of scholarly sources from psychology, sociology, neurology, and music education discourse communities. I focused on current trends in social decline, human bonding through active participation in music, and examples of group musical behavior resulting in increased prosocial skills.

\section{Results}

\section{Social Decline}

A decline in social wellness has been documented by many major government agencies, including The United Nations, The European Union, and The Australian Social Inclusion Board (Welch et al., 2014). One common factor present in this widespread phenomenon is a decrease in social cohesion, which can be defined as the degree to which the members of a community agree about, care about, and engage in efforts to accomplish common goals; how positively community members regard their 
relationships with each other and their leaders; and the level of trust among entire societies (Fonseca, Lukosch, \& Brazier, 2019).

The United States has been experiencing an overall decline of mental wellness (Jain \& Jain, 2020; Weinberger et al., 2018). Depression has been on the rise, with significantly higher rates of increase among youths. Suicide rates have also been increasing in the U.S. for the last twenty years. Today, intentionally ending one's life is the tenth leading cause of death in the U.S., and is the second leading cause of death for 10 to 34 year old Americans (Weir, 2019). These trends portray an alarming trajectory toward social decline. The prospect of continuing along this course is ample cause for serious concern, and supports the notion that an intervention will be necessary for restoring wellness in the U.S.

People are spending less and less time together. The number of dinners that families eat together, visits friends pay to each other, and organizational meetings people attend have all dropped significantly (Konrath et al., 2011). A recent survey of over twenty thousand American adults from all fifty states found a considerable prevalence of loneliness among its respondents, defined as, "a state of emotional distress from lacking desired interpersonal relationships" (Bruce et al., 2019). One of every five disclosed seldom or never feeling close enough to anyone that they feel comfortable talking to, and about half have no one in their lives that they spend quality time with regularly (Bruce et al., 2019). Loneliness was negatively correlated with age, with 18 to 22 year olds reporting the highest levels (people under the age of eighteen did not participate in the survey) (Bruce et al., 2019). 
In addition to the individual troubles associated with loneliness, like increased blood pressure, cholesterol, cardiovascular disease, and compromised immune systems, there are also risks for society as a whole (Williams \& Braun, 2019). As more people become isolated and lonely, social cohesion will likely continue deteriorating. Former United States Surgeon General Vivek Murthy (2017) warns that the loss of connectedness threatens civic engagement, putting our whole democracy in peril, and describes this as an epidemic that requires an immediate response.

\section{Music's Relationship to Wellbeing}

Music has been found to be a central feature of every known culture throughout all of human history (Buren et al., 2019; Harvey, 2018; Kirschner \& Tomasello, 2010; Loersch \& Arbuckle, 2013; Maury \& Rickard, 2016; Schellenberg et al., 2015), which means every one of us is descended from people who sang, danced, and/or played drums together. Evidence has supported hypotheses that the ubiquitousness of these types of activities can be explained by them being part of the process of human evolution (Loersch \& Arbuckle, 2013; Maury \& Rickard 2016). Researchers Loersch \& Arbuckle (2013), present the results of seven studies they conducted, which support the hypothesis that the trait of human musicality is an adaptive mechanism that has fostered the social skills necessary for the survival of Homo sapiens. They make the case that the intense emotional evocation we experience through music today can be explained by our innate drives to connect with each other.

In his extensive literature review of the history and evolutionary functions of music, Harvey (2018) explores the question of whether spoken words or music came 
into existence first, or if they were both born from a common origin. He concludes that the communication, cooperation, and social cohesion promoted by group musical interaction may have helped genetically unrelated humans to develop broader social networks than had been previously achieved. Harvey (2018) punctuates this article with the suggestion that the proof of musical behavior being a function of natural selection is self-evident, stating that it would have been selected against and extinct unless it held value for our species.

\section{Social Exclusion and Social Pain Theory}

As a social species, humans historically relied on strong bonds and cooperation with one another for survival; being excluded from their communities would have meant near certain death (Eisenberger, 2012; MacDonald \& Leary, 2005; Zhang et al., 2020). Although social pain (the emotional suffering experienced as a result of perceiving rejection from one's social group) and physical pain (the hurting one feels when damage is done to their body) have generally been considered to be separate categories of unpleasant experiences, they both appear to have more in common than was once believed (Zhang et al., 2020).

An explanation for why humans suffer from social exclusion to the extent that they do is offered by Social Pain Theory, which suggests that an adaptive function is served by feeling this way (Eisenberger, 2012; MacDonald \& Leary, 2005). This distressing experience, which is believed to date back to Earth's earliest mammals, discouraged behaviors that were potentially disruptive to communities, while promoting prosocial behaviors and social cohesion (Eisenberger, 2012). In the same way that the 
sensation of burning one's hand causes the brain to protect the flesh by sending a signal to that hand to reflexively pull away from the heat, the sting felt from social exclusion is thought to motivate inclusion and connection among social groups. In this way the negative reinforcement of this automatic aversion to social pain helped strengthen social bonds, and led to increased chances of siring viable offspring (MacDonald \& Leary, 2005).

MacDonald \& Leary (2005) further argue that because the pain system already existed in humans before the adaptive aversions to social exclusion began to evolve, it logically follows that the system that mediates threats to social inclusion would be the same as that which responds to physical pain. They also report that the two types of pain converge in thought, emotion, and behavior, and both interface with the "anterior cingulate cortex and periaqueductal gray brain structures, as well as the opioid and oxytocin neuroendocrine systems" (MacDonald \& Leary, 2005).

More support for Social Pain Theory was found by the results of functional magnetic resonance imaging (fMRI) studies that found both social and physical pain activate the same areas of the brain and depend on the same neural circuitry (Zhang et al., 2020). Despite these compelling findings, this technology is relatively new. No consensus has been reached regarding the complex relationship between these two types of pain, and will not be reached until more focused research is performed on the matter (Zhang et al., 2020). Nevertheless, it is apparent that an intimate relationship does exist between the two at a deep level; our brains interpret threats to our physical bodies and our social inclusion both as threats to our basic safety. This illuminates how 
essential our need to be connected with each other is for our emotional, psychological, and physical wellbeing.

Community music-making was found to be a potential mitigator of the pain caused by social exclusion (Dunbar, et al., 2012). The presence of community music-making as a method of social bonding in all traditional societies, and their understanding of endorphins as foundational to the relationships of all primates, inspired Dunbar, et al. (2012) to study the effects of music on endorphins and pain thresholds. They found that singing, dancing, and playing drums all increased endorphins and pain thresholds, as well as positive emotions. They concluded that the active performance of music was responsible for increases of endorphins in the central nervous system, which in turn caused elevations in thresholds of pain. Conversely, no change in pain thresholds were observed in the subjects who only listened to music, regardless of the style or tempo (Dunbar et al., 2012). To sum up, being socially excluded causes an experience nearly identical to physical pain, while playing music together reduces the amount of pain people feel, suggesting that humans are genetically hardwired to develop the social bonds needed for survival through the act of community music-making.

\section{Music, Emotional Intelligence and Empathy}

Music may produce prosocial outcomes by providing an experience of increased emotional intelligence and empathy (Konrath et al., 2011; Rabinowitch et al., 2013). The concept of "Emotional Intelligence" (EQ) began receiving widespread attention and acceptance from the general public upon the publishing of author and science journalist 
Daniel Goleman's 1995 book, Emotional Intelligence (Kaschub, 2002). This concept expanded on previous interpretations and assessments of intelligence (IQ) that focused on abilities--like organizing items by category or performing mathematics--to include awareness of one's own emotional state and the emotional states of others, as well as the ability to regulate and express one's own feelings in a socially appropriate way (Kaschub, 2002). Goleman (1995) argued for the importance of EQ, claiming that the development of higher EQ in individuals led to them living more happy and satisfying lives, as well as performing better on traditional measures of intelligence.

Empathy, a foundation of $E Q$, can be defined as "sharing of the affective state of another person, which can be triggered by direct observation, but also the mere imagination of the emotions of another person" (Lamm et al., 2019). Empathy is crucial for the wellness and success of individuals, as well as whole societies, and is believed to be the main inspiration for altruistic and prosocial behaviors (Rabinowitch et al., 2013).

In a meta-analysis of 72 samples of students attending colleges in the U.S., a decline was found in empathy and perspective taking--both fundamental components of EQ (Konrath et al., 2011). This trend began to appear in the late 1970's and early 1980's, and started to gain stronger momentum after 2000 (Konrath et al., 2011). Concern about the negative impacts of technology on EQ has captured the attention of many, and research into the matter is being performed for the purpose of discovering ways to minimize the damage technology use causes to the EQ learning process (Muhammad, et al., 2019). Regardless of what is to blame, this development should be 
concerning for all citizens. If allowed to continue unchecked, declines of empathy and perspective taking could be disastrous for the ability of our society to function (Konrath et al., 2011).

The challenges associated with developing EQ and empathy in the modern age have been identified as cause for concern by many educators (Campayo-Muñoz \& Cabedo-Mas, 2017). In their meta-analysis of 21 investigations, Campayo-Muñoz \& Cabedo-Mas (2017) found a positive correlation between learning to play an instrument and developing emotional skills. Music was determined to be a highly effective tool for helping students with getting in touch with their feelings and expressing them. For this reason, along with the gains in cognitive abilities that come along with studying music, they concluded that music education should be a standard feature in schools, because offering it to younger students would be expected to aid them in developing higher levels of $E Q$.

Research led by University of Washington fellow Dr. Tal-Chen Rabinowitch et al. (2013) also found support for their hypothesis that children who engaged in musical interaction with each other demonstrated higher levels of empathy than those who did not. They describe the findings of previous studies of pre-school and primary school students who took part in music education programs designed specifically to convey the importance of empathy and build empathetic skills (these students scored significantly higher in measures of empathy than members of the control groups). Rabinowitch et al. (2013) added to this body of evidence by designing a study of their own. They designed and implemented a program where eight to eleven year olds engaged in musical activity 
together, but no mention of empathy--explicitly or implicitly--was made to this group of students. The increase of the average empathy scores of the participants, compared with their scores before the study began and with those belonging to the control group, supports a connection between group musical behavior and the development of EQ and empathy. The medium of music has been shown to contain great potential power for strengthening the cohesion of groups automatically, even in cases when empathy building is not the focus of the program (Rabinowitch et al. 2013).

\section{Music as a Promoter of Prosocial Behavior}

Musicians and music educators have long been aware of the individual and social benefits of participating in group musical behavior from their firsthand experiences, but it is not always easy to convince the general public of these conclusions without more empirical support. Luckily for those who want to make music education available for every child, some such evidence has been collected.

Using data from The National Longitudinal Study of Adolescent Health, a comparison study was performed of adolescents who have and who have not studied the arts, while statistically controlling for other measurable covariates (Elpus, 2013). A significantly lower likelihood of delinquent behavior was found among adolescent students of music and dance. Adolescents who participated in music education were $26 \%$ less likely to consume alcohol, with a reduction of $11 \%$ for every additional year of classes; this was not true for visual art, dance, drama, or film/media arts (Elpus, 2013). Adolescents who studied music were $24 \%$ less likely to use marijuana than students who didn't, while adolescents who studied visual arts were actually $29 \%$ more likely to 
have used marijuana than their non-visual art counterparts. These benefits appear to extend beyond adolescence. Adults who studied music as adolescents were found to be significantly more optimistic than those who didn't, and former music students were also less likely to have ever used marijuana $(20.25 \%)$, cocaine $(26.55 \%)$, crystal meth (41.18\%), or other illegal drugs (25.12\%) (Elpus, 2013).

Benefits of group music involvement have also been found in younger populations. A study of eight and nine year old children who attended a ten month-long group music training program was carried out for the purpose of investigating the effects of the program on their prosocial skills (Schellenberg et al., 2015). Compared with the test results of the participants before the program and the members of the control group, the children with initially low scores who took part in the group music training showed significantly elevated levels of social skills and sympathy at the end of the study. No change was found for the children whose scores were high to begin with, but this is likely due to there being a lack of room for improvement in these areas (Schellenberg et al., 2015).

Music for Change is a project designed to support preschool aged children with delayed speech and language skills in one of the most disadvantaged areas of London, England (Knight et al., 2016). Music for Change uses a music based curriculum to improve the children's school readiness and self confidence, and develop their skills for managing feelings and making relationships (Knight et al., 2016). Not only is this ongoing project accomplishing its goal of increasing participants' social and emotional development, everyone involved has reported experiencing positive effects. The speech 
and language therapists and music leaders found empowerment through expanding their capacity to support the children, as well as gaining a deeper understanding of their roles within the school (Knight et al., 2016).

Researchers llari et al. (2020) recently investigated the prosocial effects of music with younger populations than had been studied previously. They observed positive correlations between participation in music programs and prosocial behaviors of three and four year olds. This research contributed a new element to the field by distinguishing between two specific types of prosocial behavior: sharing and instrumental helping. Both were found to increase with musical participation (llari et al., 2020). However, the exploration of the complexity of prosociality in this context is in its infancy, and more work needs to be done before it will be possible to tease apart and understand its many different dimensions.

The effects of active music making on prosociality were investigated in the youngest population to date in Buren et al.'s (2019) study of 5018 month-old children. Despite being so young that they were unable to synchronize their movements with the music or their interaction partners, a significant increase in helping behavior was observed in the children who actively engaged with music (Buren et al., 2019). This change was not found in either the group that participated in joint book reading with no music or the group that only passively listened to music. The same song performed by the same musicians was used for both the active and passive musical conditions in order to rule out the possibility that the increase in helping behavior was simply caused 
by the elevation in mood that is associated with passively listening to music (Buren et al., 2019).

In addition to the studies mentioned above, several others from diverse populations have produced similar results. 12 year old boys at high risk for school disengagement increased their levels of cooperative behavior and decreased their incidents of anti-social behaviour after completing 10 weeks of a group drumming class (Maury \& Rickard, 2016). A comparison study of 700 nine and twelve year olds who either extended their music education or other subjects, like visual arts and sports, found the youths in the music group expressed more pride and satisfaction with their classes and reported less bullying than the other groups (Eerola \& Eerola, 2014). A statistically significant positive correlation was observed between group singing and cooperative problem solving behavior in a study of four year olds (Kirschner \& Tomasello, 2010). Canadian primary school students who sang in groups together scored higher on measures of cooperation than those who made art together or played competitive games (Good \& Russo, 2016). Italian preschoolers demonstrated higher levels of empathy after 24 weeks of music education, compared with a control group who did not (Ilari et al., 2020). In a correlational study of 3,031 families in Australia, prosocial behaviours of four and five year olds were predicted by the frequency of interactive musical activities they shared with their parents when they were two and three years old (Williams et al., 2015). The act of making music with others clearly leads to increases of cooperation and empathy, as well as strengthening group ties and social 
cohesion, regardless of what culture one belongs to. Group music interaction appears to have the power to make any society healthier.

\section{Discussion}

Humans have never been the strongest or fastest creatures on Earth. The human race has been able to survive by cooperating with each other (Loersch \& Arbuckle, 2013; MacDonald \& Leary, 2005), and without engaging in this all-important activity, it is unlikely that we would be able to continue inhabiting our planet the way we do today. I believe harmonious and cooperative relationships are essential for being a healthy and complete person, and I suspect the current decline in social wellness (Jain \& Jain, 2020; Weinberger et al., 2018; Weir, 2019; Welch et al., 2014) can be attributed to the decrease in real-time face-to-face cooperative behavior available within our current paradigm.

Isolation and loneliness are on the rise (Bruce et al., 2019), while at the same time empathy is declining, and these changes are strongly correlated with the increase of the daily use of smartphones with access to the internet and social media (Konrath et al., 2011). It is very difficult to believe that people having more of their social interactions online, and less in person, isn't having a negative effect on their ability to function as the cooperative species that we are--and there is no end to this trend in sight. The expanding capacity for people to connect with each other with the aid of technology may be actually creating more distance between us. It is doubtful that any intimacy gained by this method of communication is sufficient; humans appear to need real-world in-person interactions, not just images on screens, to satisfy their needs for social bonding 
(Konrath et al., 2011). I fear that losing our connection to each other is presenting a grave threat to our collective ability to continue being an extant species.

Writing this thesis has been a very personal journey. Before I started, I understood how important music has been for me in my own life. Music has been my teacher, a means of connecting with other people, and a way to demonstrate my worth to myself and the communities I belong to. I honestly can't imagine who or where I would be without it. Through the years of performing in public, I discovered my special relationship with music is more common than I realized. Countless times, people have shared with me their stories of how their relationship with music was the one thing that helped them stay grounded and got them through the most difficult times in their lives. Of course, these people were all concertgoers, so I didn't assume what they said would apply to everybody.

I now have an expanded appreciation for the power of music, and for how universal its effectiveness seems to be for promoting prosociality. Learning that active group music behavior has been part of all known human societies since long before recorded history (Buren et al., 2019; Harvey, 2018; Kirschner \& Tomasello, 2010; Loersch \& Arbuckle, 2013; Maury \& Rickard, 2016; Schellenberg et al., 2015), and has been found to result in significant prosocial benefits across many cultures (Good \& Russo, 2016; Ilari, Helfter, \& Huynh, 2020; Maury \& Rickard, 2016; Williams et al., 2015), has led me to the conclusion that making music together is an essential component of social wellness. I now strongly believe that using music for fostering social bonds and developing social skills for our youths can have a ripple effect of 
improving whole communities. I also believe that we have reached a critical point in the story of humankind, and will likely continue heading in the dangerous direction of more isolation. While l'm not naive enough to think any single intervention would be enough to turn it all around, it does seem to me like we should be doing everything we can to mitigate the damage being caused by our current trajectory. If music education offers the potential to restore any social wellness at all, I can't understand why we wouldn't all agree to use it, and I would challenge anyone opposing this proposal with this question: what could be the downside of it?

\section{Conclusions}

Active participation in group music-making is an essential component for healthy societies and the individuals that comprise them (Dunbar et al., 2012; Loersch \& Arbuckle, 2013; Welch et al., 2014). I believe humanity's relatively recent shift from ubiquitous communal music-making to solitary passive listening (Attali, 1985) fails to serve its evolutionary purpose of promoting social cohesion, and is at least partially responsible for people feeling less connected to the cultures they belong to. Without the realization of our connectedness, what incentive do we have to contribute to our communities? If we fail to remember how to work together, the continued decline of our civilization seems imminent. If people keep losing connection with each other, we will continue to lose essential aspects of being human. A world without empathy would be a world at war with itself. 
Music education in preschools and primary schools has the potential to restore social wellness by providing opportunities for our youth to increase their feelings of social inclusion and form social bonds through the act of community music-making. In this way, music education may be an effective antidote to our current and impending social decline. If something as simple and intuitive as people playing music together can facilitate a greater opportunity for communities to coalesce and thrive together, doing so would be a valuable use of our resources and a realistic step for us to take; the sooner we do, the better off we all will be. Hopefully, researchers will continue to study the power that music offers for improving the ability of communities to function and flourish, and eventually accumulate enough evidence to convince our leaders and the general public of the need to make music education available to every child.

\section{Limitations}

It is important for me to acknowledge my bias regarding the value of music education. Although my research led me to a plethora of consistent empirical evidence that supported my arguments, the profound benefits I have personally experienced through group music-making surely colored the lens through which I viewed that data. Also, as is often the case in the social sciences, the multitude of variables at play with humans and their behavior makes proving causation a very difficult task. However, a body of evidence with consistent results has been increasing, and more measures keep being taken to isolate group music-making as the variable that is the cause of positive changes. For instance, the program reported by Schellenberg et al. (2015) was compulsory, in order to control for the possibility that children who joined music groups 
or classes had more prosocial attitudes and behaviors to begin with. And in their study of 4 year olds, Kirschner and Tomasello (2010) isolated the effects of music by having their control group perform the same activities as the children in the treatment group, with the same goals, movements, and spoken comments. Having said that, much more work needs to be done before this phenomenon can be fully understood.

\section{References}

Attali, Jacques. (1985). Noise: The Political Economy of Music. Theory and History of Literature, Volume 16. University of Minnesota Press. Minneapolis, MN.

Bettmann, J. E., Anstadt, G., Casselman, B., \& Ganesh, K. (2020). Young Adult Depression and Anxiety Linked to Social Media Use: Assessment and Treatment.

Clinical Social Work Journal, 1-12.

Bruce, L. D., Wu, J. S., Lustig, S. L., Russell, D. W., \& Nemecek, D. A. (2019). Loneliness in the United States: a 2018 national panel survey of demographic, structural, cognitive, and behavioral characteristics. American Journal of Health Promotion, 33(8), 1123-1133. 
Buren, V., Degé, F., \& Schwarzer, G. (2019). Active Music Making Facilitates Prosocial Behaviour in 18-month-old Children. Musicae Scientiae, 1029864919892308.https://journals-sagepub-com.proxy.lib.pdx.edu/doi/full/10.11 $\underline{77 / 1029864919892308}$

Campayo-Muñoz, E. Á., \& Cabedo-Mas, A. (2017). The role of emotional skills in music

education. British Journal of Music Education, 34(3), 243-258.

Dunbar, R., Kaskatis, K., Macdonald, I., \& Barra, V. (2012). Performance of Music Elevates Pain Threshold and Positive Affect: Implications for the Evolutionary Function of Music. Evolutionary Psychology, 10(4), 688-702.

Eerola, P.-S., \& Eerola, T. (2014). Extended music education enhances the quality of school life. Music Education Research, 16(1), 88-104. doi:10.1080/14613808.2013.829428

Eisenberger, N. I. (2012). Broken hearts and broken bones: A neural perspective on the similarities between social and physical pain. Current Directions in Psychological Science, 21(1), 42-47.

Elpus, K. (2013). Arts education and positive youth development: Cognitive, behavioral, and social outcomes of adolescents who study the arts. National Endowment for the Arts, 1-56. 
Fonseca, X., Lukosch, S., \& Brazier, F. (2019). Social cohesion revisited: a new definition and how to characterize it. Innovation: The European Journal of Social Science Research, 32(2), 231-253. Doi: https://www.tandfonline.com/doi/full/10.1080/13511610.2018.1497480

Goleman, D. (1995). Emotional intelligence. New York: Bantam Books.

Good, A., Russo, F. (2016). Singing promotes cooperation in a diverse group of children.

Social Psychology, 47, 340-344. doi:10.1027/1864-9335/a000282

Gould, S. J., \& Lewontin, R. C. (1979). The spandrels of San Marco and the Panglossian paradigm: a critique of the adaptationist programme. Proceedings of the royal society of London. Series B. Biological Sciences, 205(1161), 581-598.

Harris, L. J. (2019). Does music matter? A look at the issues and the evidence.

Developmental neuropsychology, 44(1), 104-145.

Harvey, A. R. (2018). Music and the meeting of human minds. Frontiers in psychology, 9 , 762.

Ilari, B., Helfter, S., \& Huynh, T. (2020). Associations Between Musical Participation and Young Children's Prosocial Behaviors. Journal of Research in Music Education, 67(4), 399-412. 
Jain, R., \& Jain, S. (2020). The science and practice of wellness: interventions for happiness, enthusiasm, resilience, and optimism (Hero). Retrieved from https://books.google.com/books?hl=en\&lr=\&id=ETbDDwAAQBAJ\&oi=fnd\&pg=PT $\underline{9}$

Kaschub, M. (2002). Defining emotional intelligence in music education. Arts Education Policy Review, 103(5), 9-15. Retrieved from http://stats.lib.pdx.edu/proxy.php?url=http://search.proquest.com.proxy.lib.pdx.ed u/docview/211025402?accountid=13265

Kirschner, S., \& Tomasello, M. (2010). Joint music making promotes prosocial behavior in

4-year-old children. Evolution and Human Behavior, 31(5), 354-364.

https://www-sciencedirect-com.proxy.lib.pdx.edu/science/article/pii/S1090513810 $\underline{000462}$

Konrath, S., O'Brien, E., \& Hsing, C. (2011). Changes in Dispositional Empathy in American College Students Over Time: A Meta-Analysis. Personality and Social Psychology Review, 15(2), 180-198.

Knight, J., Bowmer, A., \& Welch, G. (2016). Music for Change 2015-18: Collaborating with

Speech and Language Therapists: a multi-perspective report. Creative Futures. 
Lamm, C., Rütgen, M., \& Wagner, I. C. (2019). Imaging empathy and prosocial emotions.

Neuroscience letters, 693, 49-53

Loersch, C., \& Arbuckle, N. L. (2013). Unraveling the mystery of music: Music as an evolved group process. Journal of Personality and Social Psychology, 105(5), 777-798. doi:http://dx.doi.org.proxy.lib.pdx.edu/10.1037/a0033691

MacDonald, G., \& Leary, M. R. (2005). Why does social exclusion hurt? the relationship between social and physical pain. Psychological Bulletin, 131(2), 202-223. http://stats.lib.pdx.edu/proxy.php?url=http://search.proquest.com.proxy.lib.pdx.ed $\underline{\text { u/docview/62131873?accountid }=13265}$

Maury, S., \& Rickard, N. (2016). Wellbeing in the Classroom: How an Evolutionary Perspective on Human Musicality Can Inform Music Education. Australian Journal

of Music Education, 50(1), 3-15.

Muhammad, N.M., Schneider, M., Hill, A. \& Yau, D.M. (2019). The Negative Impacts of EdTech: EQ Perspectives. In K. Graziano (Ed.), Proceedings of Society for Information Technology \& Teacher Education International Conference (pp. 1066-1071). Las Vegas, NV, United States: Association for the Advancement of Computing in Education (AACE). Retrieved April 16, 2020 from https://www.learntechlib.org/primary/p/207777/.

Murthy, V. (2017). Work and the loneliness epidemic. Harvard Business Review. 
Retrieved from

https://hbr.org/cover-story/2017/09/work-and-the-loneliness-epidemic

Rabinowitch, T. C., Cross, I., \& Burnard, P. (2013). Long-term musical group interaction has a positive influence on empathy in children. Psychology of music, 41(4), 484-498.

Schellenberg, E. G., Corrigall, K. A., Dys, S. P., \& Malti, T. (2015). Group music training and children's prosocial skills. PLoS One, 10(10).

Shaer, M. (2018, March 01). The Archaeology of Wealth Inequality. https://www.smithsonianmag.com/history/aracheology-wealth-inequality-1809680 $\underline{721}$

Tayag, Y. (2017, November 15). Societies Are Headed Toward Revolution, Suggests Inequality Study. https://www.inverse.com/article/38457-inequality-study-nature-revolution

Weinberger, A. H., Gbedemah, M., Martinez, A. M., Nash, D., Galea, S., \& Goodwin, R. D. (2018). Trends in depression prevalence in the USA from 2005 to 2015 : widening disparities in vulnerable groups. Psychological Medicine, 48(8), 1308-1315. doi: 10.1017/s0033291717002781

Weir, K. (2019). Worrying trends in U.S. suicide rates. Monitor on Psychology, 50(3), 24. doi: https://www.apa.org/monitor/2019/03/trends-suicide

Welch, G. F., Ehimonides, E., Esaunders, J., Epapageorgi, I., \& Esarazin, M. (2014). 
Singing and social inclusion. Frontiers in Psychology, 5, 803.

doi.org/10.3389/fpsyg.2014.00803

Williams, Kate E, Barrett, Margaret S, Welch, Graham F, Abad, Vicky, \& Broughton, Mary.

(2015). Associations between early shared music activities in the home and later child outcomes: Findings from the Longitudinal Study of Australian Children.

Early

Childhood Research Quarterly., 31, 113-124.

Williams, S. E., \& Braun, B. (2019). Loneliness and Social Isolation--A Private Problem, A

Public Issue. Journal of Family \& Consumer Sciences, 111(1).

Zhang, M., Zhang, Y., \& Kong, Y. (2020). Interaction between social pain and physical pain. Brain Science Advances, 5(4), 265-273. 